\title{
AÇÃO DE REGULADORES VEGETAIS NO CRESCIMENTO DE TOMATEIRO (Lycopersicon esculentum Mill. cv. «Miguel Pereira»)*
}

\author{
Paulo R. C. Castro ** \\ EURÍPEDEs MaLavolta ***
}

\author{
RESUMO
}

Estudaram-se em condições de casa de vegetação, os efeitos da aplicação de reguladores vegetais no crescimento do tomateiro cultivar "Miguel Pereira". Além do tratamento controle, aplicou-se, 44 dias após a semeadura, cloreto de (2-cloroetil) trimetilamônio $2.000 \mathrm{ppm}$, ácido succínico -2,2-dimetilhidrazida $3.000 \mathrm{ppm}$ e ácido giberélico $100 \mathrm{ppm}$. Observou-se que o GA promoveu maior crescimento, em relação ao controle. $\mathrm{O}$ crescimento do tomateiro mostrou-se mais reduzido nas plantas tratadas com CCC e SADH, com relação àquelas pulverizadas com GA e plantas controle.

\section{TNTRODUÇĀO}

Com a descoberta da América, verificou-se que o tomateiro proliferava no México, América Central e América do Sul. Diversos pesquisadores consideraram que o centro de origem do tomateiro é a região compreendida pelo Peru e Equador. JENKINS (1948) observou que tal centro não é necessariamente idêntico ao ponto de diversificação das formas cultivadas, sugerindo que a área entre Puebla e Vera Cruz, no México, é um centro de diversificação varietal que tem originado as formas cultivadas. Desde a revisão efetuada por MULLER (1940) tem-se considerado correta a designação de Lycopersicon esculentum, ao tomateiro. BAILEY (1949) reconhece somente duas espécies: L. pimpinellifolium

\footnotetext{
* Trabalho subvencionado pela Fundação de Amparo à Pesquisa do Estado de São Paulo (FAPESP); parte da Tese apresentada pelo primeiro autor para obtenção do título de Doutor pela U.S.P. Entregue para publicação em 17/8/1976.

** Departamento de Botânica. E.S.A. "Luiz de Queiroz" - U.S.P.

*** Departamento de Química e CENA. E.S.A. "Luiz de Queiroz" - U.S.P.

OBS.: Considerar aspas duplas referentes às cultivares como sendo aspas simples.
} 
e L. esculentum, esta última com as variedades botânicas: commune, tomateiro comum; grandifolium, tomateiro folha de batata; validum, ereto ou arbustivo; cerasiforme, tomate sereja e pyriforme, tomate pera. MULLER (1940) reconhece quatro espécies adicionais às duas anteriormente mencionadas: $L$. cheesmanii, L. peruvianum, $L$. hirsutum e L. glandulosum.

RICK (1958) estudando tomateiros silvestres e espécies afins no Equador, Peru e norte do Chile, observou que, ao contrário do que ocorre com o tomateiro comum, que é principalmente autógamo, verifica-se muito cruzamento natural entre as espécies silvestres que desenvolveram-se em seu próprio habitat. Considerou que o alto índice de cruzamento tem produzido muita variabilidade, favorecendo a rápida evolução de novas formas. As cultivares atuais de tomateiro apresentam características morfológicas e de crescimento bastante variáveis devido a complexidade de suas origens.

Apesar do crescimento do tomateiro sob efeito de reguladores de crescimento ter sido estudado por diversos autores, pouco se conhece da análise do desenvolvimento desta planta. WITTWER \& TOLBERT (1960) verificaram que a aplicação de cloreto de (2-cloroetil) trimetilamônio (CCC), nas concentrações de $10^{-3}$ a $10^{-7} \mathrm{M}$ nas raízes de tomateiros, alterou grandemente o crescimento e promoveu florescimento precoce. As plantas tratadas desenvolveram hastes grossas e folhas verde-escuras. As alterações no crescimento foram opostas e mais persistentes que aquelas induzidas por giberelina. Uma regulação na magnitude do crescimento e no acúmulo de matéria seca, nas plantas de tomateiro, seguiu-se à aplicação do produto em concentrações crescentes nas soluções de cultivo. Essa resposta no crescimento variou de um estímulo a $10^{-7} \mathrm{M}$, a uma pronunciada supressão a $10^{-4} \mathbf{M}$, sem atrasar o florescimento ou provocar injúria visível. CASTRO \& CHURATA-MASCA (1973) efetuaram aplicação de CCC nas concentrações de $0,1.500,2.000$ e 2.500 ppm em pulverização e na dosagem de $4.000 \mathrm{ppm}$ em irrigação, no tomateiro. O produto foi aplicado 15 dias após o transplante. Observaram que o CCC provocou redução altamente significativa no comprimento dos meritalos quando aplicado nas concentrações de 2.500 ppm em pulverização e 4.000 ppm em irrigação. Notaram aumento significativo no número de meritalos nas plantas tratadas com $2.500 \mathrm{ppm}$ de CCC em pulverização; sendo que a redução em altura provocada pelo CCC não mostrou-se significativa com relação ao controle. MORGAN \& HENNERTY (1968) observaram que o tratamento de plantas jovens de tomateiro com CCC e ácido succínico -2,2-dimetilhidrazida (SADH) reduziu significativamente a área foliar, o espalhamento da planta, o peso da matéria seca, a altura e o número de folhas. Geralmente uma aplicação dupla é mais eficiente do que uma única aplicação, inicial ou tardia. O produto químico mostrou-se mais efetivo quando aplicado em altas concentrações, na maioria dos casos. O CCC foi superior ao $\mathrm{SADH}$ em diversos aspectos e revelou-se mais eficiente quando aplicado em irrigação, a concentrações elevadas. 
O CCC reduziu a altura mais eficientemente sob alta intensidade luminosa, indicando uma provável interação entre o CCC e a luz. As mais altas concentrações de CCC e SADH (1.500 e 3.000 ppm) induziram sintomas de injúria, que se apresentaram como clorose e necrose marginal no caso do CCC; sendo que o SADH provocou enrugamento foliar. KNAVEL (1969) verificou o efeito de retardadores de crescimento em tomateiro, desenvolvendo-se em dois substratos distintos. CCC e SADH foram aplicados quando as plantas apresentavam a terceira folha verdadeira. Observou que o CCC foi mais efetivo na redução do crescimento, com relação ao SADH, indiferentemente ao nível de fertilidade. $\mathrm{SADH}$ revelou afetar o crescimento do tomateiro em ambos os substratos utilizados. NORMAN (1972) efetuou ensaios em condições de vaso e de campo para observar o efeito do SADH em tomateiro. Aplicações de SADH nas dosagens de 1.000 e 2.000 ppm retardaram o crescimento das plantas no estágio inicial. Esses efeitos diminuiram 4 semanas após a aplicação do regulador de crescimento. TAHA et alii (1975) observaram que plantas de tomateiro submetidas à poda ou tratadas com SADH tenderam a ficar compactas e a apresentarem hastes mais grossas do que aquelas tratadas com ácido (2-cloroetil) fosfônico (CEPA). CEPA aumentou o conteúdo de matéria seca em plantas jovens, mas parece não afetar plantas adultas. Apareceram poucas flores em plantas jovens tratadas com CEPA ou com SADH + CEPA, mas novamente esse efeito não foi aparente em grupos de plantas mais adultas. SADH aplicado em plantas muito jovens atrasou o desenvolvimento das plantas e dos frutos de tomateiro, sendo que o CEPA não atrasou esse desenvolvimento. Efeitos de tratamentos com CEPA ou SADH em plantas adultas, não se mostraram evidentes.

GRAY (1957) verificou que plantas de tomateiro tratadas com $10 \mathrm{ppm}$ de ácido giberélico, quando transplantadas, cresceram 10 vezes mais do que as plantas não tratadas, durante os 4 dias seguintes ao transplante, sendo que as plantas continuaram a crescer mais do que o controle durante a segunda e terceira semanas. SIMÃO et alii (1958) observaram que plantas de tomateiro tratadas com ácido giberélico mostraram perda de coloração nas folhas e hastes, tanto mais acentuadamente quanto maior a concentração da solução de ácido giberélico aplicada. As hastes e as folhas se alongaram de maneira mais acentuada. nos primeiros dez dias após a pulverização, nos tratamentos com $10 \mathrm{e}$ $50 \mathrm{ppm}$ de ácido giberélico. De um modo geral, as plantas tratadas com ácido giberélico atingiram um maior desenvolvimento; mas a diferença desaparecia após cerca de quinze dias. RAPPAPORT (1958) trabalhando com ácido giberélico nas concentrações de 100 e $200 \mathrm{mg}$ por planta, observou intenso alongamento da haste do tomateiro. O alongamento em plantas novas ocorreu em todas as dosagens entre 2 e $450 \mathrm{mg}$ por planta. O peso da matéria seca das plantas de tomateiro também foi aumentado; sendo que observou, ainda, incremento nas dimensões foliares. PLUMMER \& TOMES (1958) estudando 4 variedades normais e 4 linhagens anãs de tomateiro, não obtiveram aumento significativo na altura das plantas, quando tratadas com ácido indo- 
lacético (IAA). Entretanto, as plantas anãs, quando tratadas com ácido giberélico, excederam em altura as plantas normais não tratadas; sendo que esse aumento significativo no crescimento ocorreu em todas as variedades. MIRANDA NETO \& CHAVES (1969) não observaram diferenças significativas na altura de tomateiros tratados com ácido giberélico nas concentrações de 50 e 100 ppm e ácido paracloro-fenoxiacético nas dosagens de 25 e 50 ppm, com relação às plantas não tratadas.

O presente trabalho teve como finalidade estudar os efeitos de reguladores vegetais no crescimento em altura do tomateiro cultivar "Miguel Pereira".

\section{MATERIAIS E MÉTODOS}

Iniciou-se o experimento em 21 de fevereiro de 1974, em Piracicaba (SP), tendo-se nesta ocasião realizado a semeadura do tomateiro cultivar "Miguel Pereira" em caixa de madeira contendo solo esterilizado, no interior de casa de vegetação. O transplante foi efetuado em 05/03/74 para vaso de cerâmica com 14 litros de capacidade total e com 12 litros de solo com 1,5\% de carbono orgânico; $\mathrm{pH} 6,0 ; \mathrm{Al}$ e $\mathrm{Ca}+\mathrm{Mg}$ nos teores de, respectivamente, 0,0 e 2,9 e. $\mathrm{mg} / 100 \mathrm{ml}$ de T.F.S.A.; finalmente 0,2 e 0,1 e. $\mathrm{mg} / 100 \mathrm{ml}$ de T.F.S.A., de $\mathrm{K}$ e $\mathrm{P}$, respectivamente. Colocaram-se três plântulas por vaso no transplante, tendo-se realizado o desbaste de duas delas em 28/03/74. Efetuaram-se os tratos culturais normais para o tomateiro.

Além do tratamento controle aplicou-se cloreto de (2-cloroetil) trimetilamônio (CCC) na concentração de $2.000 \mathrm{ppm}$, ácido succínico -2,2-dimetilhidrazida (SADH) 3.000 ppm e ácido giberélico (GA) 100 ppm. O delineamento experimental utilizado foi inteiramente casualizado com 10 repetições, tendo-se mantido uma planta por vaso por repetição. Procedeu-se a comparação de médias pelo teste de Tukey, calculando-se a diferença mínima significativa (D.M.S.) ao nível de $5 \%$ de probabilidade.

As aplicações dos reguladores de crescimento foram efetuadas em 05/04/74 por pulverização, até que as folhas ficassem completamente molhadas. As mensurações da altura foram realizados a partir de 01/04/74 (antes da aplicação dos fitohormônios), com intervalos de 7 dias; efetuando-se a medida desde a região do colo até a extremidade apical da planta. Assim sendo, novas mensurações foram realizadas em 08/04, 15/04, 22/04 e finalmente em 06/05/74, momento do pleno florescimento. Efetuou-se a análise estatística das variações semanais em altura com relação aos valores obtidos antes da aplicação dos reguladores de crescimento. 
Tabela 1 - Efeito da aplicação de reguladores de crescimento em $05 / 04 / 74$ tıa variação em altura de tomateiros, em $\mathrm{cm}$, no período de 01 a 08/04/74.

\begin{tabular}{|c|c|c|c|c|c|c|c|c|c|c|}
\hline $\begin{array}{l}\text { Trata- } \\
\text { mento }\end{array}$ & & & & & Repetições & & & & & Média \\
\hline Controle & 20,00 & 16,00 & 25,00 & 21,00 & $11,00 \quad 27,00$ & 23,00 & 28,00 & 21,00 & 9,00 & 20,1000 \\
\hline $\mathrm{CCC}$ & 22,00 & 15,00 & 13,00 & 13,00 & $20,00 \quad 14,00$ & 22,00 & 15,00 & 14,00 & 17,00 & 16,5000 \\
\hline SADH & 9,00 & 8,00 & 14,00 & 5,00 & $17,00 \quad 8,00$ & 15,00 & 5,00 & 13,00 & 8,00 & 10,2000 \\
\hline GA & 25,00 & 22,00 & 35,00 & 24,00 & $24,00 \quad 18,00$ & 34,00 & 28,00 & 24,00 & 24,00 & 25,8000 \\
\hline
\end{tabular}

O teste $\mathbf{F}$ para tratamentos mostrou valor da ordem de 17,3193 , significativo ao nível de $1 \%$ de probabilidade. A diferença mínima significativa pelo teste de Tukey, ao nível de $5 \%$ de probabilidade, foi de 5,9921. Observando-se as diferenças entre as médias, notamos que as plantas tratadas com GA e as plantas controle apresentaram-se com maiores variações em altura, com relação às tratadas com SADH, no período considerado. Tratamento com GA promoveu maior variação em altura, com relação às plantas tratadas com CCC. O coeficiente de variação foi de $27,37 \%$.

Tabela 2 - Efeito da aplicação de reguladores de crescimento em 05/04/74 na variação em altura de tomateiros, em $\mathrm{cm}$, no período de 01 a 15/04/74.

\begin{tabular}{|c|c|c|c|c|c|c|c|c|c|c|}
\hline $\begin{array}{l}\text { Trata- } \\
\text { mento }\end{array}$ & & & & & Repetições & & & & & Média \\
\hline Controle & 34,00 & 36,00 & 47,00 & 41,00 & $24,00 \quad 51,00$ & 47,00 & 50,00 & 38,00 & 22,00 & 39,0000 \\
\hline $\mathrm{CCC}$ & 32,00 & 24,00 & 19,00 & 18,00 & $27,00 \quad 18,00$ & 34,00 & 22,00 & 21,00 & 23,00 & 23,8000 \\
\hline SADH & 17,00 & 16,00 & 15,00 & 10,00 & $29,00 \quad 15,00$ & 27,00 & 12,00 & 23,00 & 14,00 & 17,8000 \\
\hline GA & 48,00 & 50,00 & 62,00 & 48,00 & $48,00 \quad 46,00$ & 62,00 & 56,00 & 47,00 & 47,00 & 51,4000 \\
\hline
\end{tabular}

O teste $F$ para tratamentos apresentou valor de 42,5723 , significativo ao nível de $1 \%$ de probabilidade. A diferença mínima significativa pelo teste de Tukey, ao nível de $5 \%$ de probabilidade, foi da ordem de 8,8665 . Verificando-se as diferenças entre as médias, observamos que as plantas tratadas com GA e as plantas controle mostraram-se com maiores variações em altura, com relação àquelas tratadas com SADH e CCC. Tratamento com GA promoveu maior variação em altura, com relação ao controle. O coeficiente de variação foi de $22,27 \%$. 
Tabela 3 - Efeito da aplicação de reguladores de crescimento em $05 / 04 / 74$ na variaçào em altura de tomateiros, em $\mathrm{cm}$, no período de 01 a 22/04/74.

\begin{tabular}{|c|c|c|c|c|c|c|c|c|c|c|}
\hline $\begin{array}{l}\text { Trata- } \\
\text { mento }\end{array}$ & & & & & Repetições & & & & & Média \\
\hline Controle & 53,00 & 58,00 & 70,00 & 60,00 & $50,00 \quad 72,00$ & 77,00 & 69,00 & 49,00 & 44,00 & 60,2000 \\
\hline $\mathrm{CCC}$ & 25.00 & 41,00 & 8,00 & 26,00 & $36,00 \quad 25,00$ & 44,00 & 32,00 & 27,00 & 29,00 & $29,30(x)$ \\
\hline SADH & 31,00 & 26,00 & 38,00 & 19,00 & $38,00 \quad 29,00$ & 43,00 & 28,00 & 37,00 & 22,00 & 31,1000 \\
\hline GA & 66,00 & 66,00 & 86,00 & 60,00 & $62,00 \quad 66,00$ & 86,00 & 74,00 & 70,00 & 62,00 & 69,8010 \\
\hline
\end{tabular}

0 teste $\mathbf{F}$ para tratamentos apresentou valor da ordem de 44,4235 , significativo ao nível de $1 \%$ de probabilidade. A diferença mínima significativa pelo teste de Tukey, ao nível de $5 \%$ de probabilidade, foi de 11,7214. Observando-se as diferenças entre as médias verificamos que as plantas tratadas com GA e as plantas controle mostraram-se com maiores variações em altura, com relação àquelas tratadas com CCC e SADH. O coeficiente de variação foi de $20,41 \%$.

Tabela 4 - Efeito da aplicação de reguladores de crescimento em $05 / 04 / 74$ na variação em altura de tomateiros, em $\mathrm{cm}$, no período de 01 a 29/04/74.

\begin{tabular}{|c|c|c|c|c|c|c|c|}
\hline $\begin{array}{l}\text { Trata- } \\
\text { mento }\end{array}$ & & & Repetições & & & & Média \\
\hline Controle & $75,00 \quad 77,00$ & $91,00 \quad 75,00$ & $55,00 \quad 83,00$ & $105,00 \quad 84,00$ & 62,00 & 61,00 & 76,8000 \\
\hline $\mathrm{CCC}$ & $67,00 \quad 64,00$ & $45,00 \quad 40,00$ & $42,00 \quad 30,00$ & $54,00 \quad 38,00$ & 47,00 & 36,00 & 46,3000 \\
\hline SADH & $45,00 \quad 36,00$ & $53,00 \quad 33,00$ & $47,00 \quad 52,00$ & $54,00 \quad 51,00$ & 61,00 & 32,00 & 46,4000 \\
\hline GA & $90,00 \quad 82,00$ & $108,00 \quad 69,00$ & $97,0081,00$ & $115,00 \quad 97,00$ & 101,00 & 78,00 & 91,8000 \\
\hline
\end{tabular}

O teste $\mathbf{F}$ para tratamentos mostrou valor de 30,6975 , significativo ao nível de $1 \%$ de probabilidade. A diferença mínima significativa pelo teste de Tukey, ao nível de $5 \%$ de probabilidade, foi da ordem de 15,6607. Verificando-se as diferenças entre as médias, observamos que as plantas tratadas com GA e as plantas controle apresentaram-se com maiores variações em altura, com relação àquelas tratadas com CCC e SADH. O coeficiente de variação foi de 19,87 . 
Tabela 5 - Efeito da aplicação de reguladores de crescimento em 05/04/74 na variação em altura de tomateiros, em $\mathrm{cm}$, no período de 01/04 a 06/05/74.

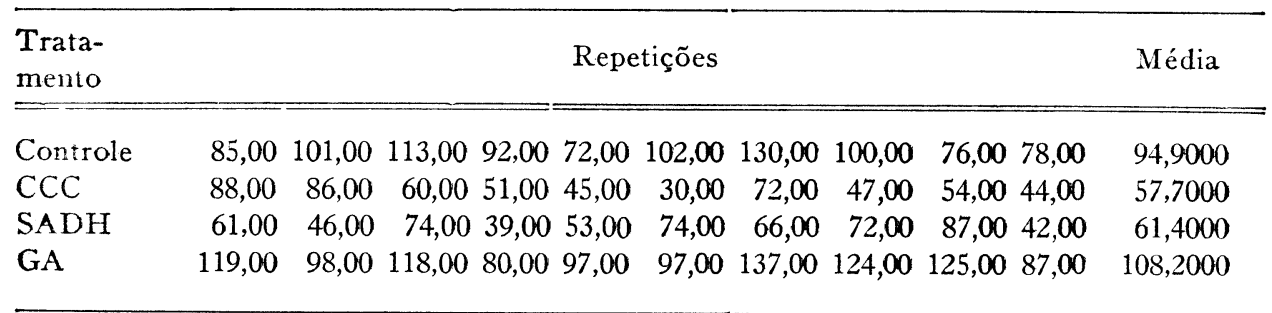

O teste $\mathrm{F}$ para tratamentos mostrou valor da ordem de 19,1827 , significativo ao nível de $1 \%$ de probabilidade. A diferença mínima significativa pelo teste de Tukey, ao nível de $5 \%$ de probabilidade, foi de 21,6789. Observando-se as diferenças entre as médias, notamos que as plantas tratadas com GA e as plantas controle apresentaram-se com maiores variações em altura, com relação às pulverizadas com CCC e SADH. O coeficiente de variação foi de $22,31 \%$.

\section{DISCUSSÃO}

Neste ensaio estudou-se o crescimento em altura do tomateiro em intervalos semanais a partir de $01 / 04 / 74$, tendo-se efetuado a aplicação de CCC, SADH e GA em 05/04/74. Na primeira semana (01 a 08/04/74), observou-se que as plantas tratadas com SADH mostraram menor variação em altura, com relação àquelas tratadas com GA e às plantas controle. Notou-se também que o tratamento com CCC promoveu menor variação na alura, em relação às plantas pulverizadas com GA (tabela 1). Estes resultados mostram-se semelhantes aos obtidos por NORMAN (1972), que observou que o SADH retardou o crescimento do tomateiro em seu estágio inicial de desenvolvimento; sendo que WITTWER \& TOLBERT (1960) notaram que o CCC promove redução no crescimento do tomateiro. GRAY (1975) verificou que o GA causou pronunciado aumento no desenvolvimento do tomateiro. Na segunda semana (01 a 15/04/74), verificou-se que as plantas tratadas com SADH e CCC apresentaram menor variação em altura, com relação às tratadas com GA e plantas controle. Observou-se ainda que aplicação de GA causou maior variação em altura, com relação às plantas controle (tabela 2). KNAVEL (1969) notou que o CCC e SADH mostraram-se efetivos na redução do crescimento de tomateiro. RAPPAPORT (1958) verificou que o GA promoveu grande aumento no crescimento do tomateiro. Na 3. ${ }^{\mathrm{a}}, 4 .^{\mathrm{a}}$ e $5 .^{\mathrm{a}}$ semanas, observaram-se resultados semelhantes: plantas tratadas com CCC e SADH mostraram menor variação em altura, com relação às tratadas com GA e plantas controle (tabelas 3, 
4 e 5). Estes resultados estão de acordo com KNAVEL (1969), que verificou que o CCC revelou-se mais efetivo na redução do crescimento do tomateiro, com relação ao SADH. NORMAN (1972) observou que o SADH retardou o crescimento inicial do tomateiro, sendo que esse efeito diminuiu 4 semanas após a aplicação do regulador de crescimento. GRAY (1957) verificou que o GA promoveu grande aumento no crescimento do tomateiro, no transplante, sendo que a diferença com relação ao controle manteve-se durante a $2 .^{\text {a }}$ e $3 .^{\text {a }}$ semanas. SIMÃO et alii (1958) notaram que, apesar das plantas tratadas com GA atingirem um maior crescimento em relação ao controle, nos dez dias posteriores à pulverização, a diferença desapareceu após cerca de 15 dias.

\section{CONCLUSÕES} clusôes:

Os resultados obtidos neste ensaio, permitem as seguintes con-

1. O ácido succínico -2,2-dimetilhidrazida retarda mais efetivamente o crescimento do tomateiro nos primeiros 10 dias após sua aplicação.

2. O cloreto de (2-cloroetil) trimetilamônio retarda mais pronunciadamente o crescimento do tomateiro além de 25 dias após sua aplicação.

3. O ácido giberélico acelera efeivamente o crescimento do tomateiro antes de 4 dias e até além de 30 dias após sua aplicação.

SUMMARY

ACTION OF PLANT REGULATORS IN THE GROWTH OF TOMATO (LYCOPERSICON ESCULENTUM MILL. cv. "MIGUEL PEREIRA").

This research deals with the effects of exogenous growth regulators on development of the tomato cultivar «Miguel Pereira». Observations of tomato plants treated with (2-chloroethyl) trimethylammonium chloride $(2,000 \mathrm{ppm})$ and succinic acid -2,2-dimethylhydrazide $(3,000 \mathrm{ppm})$ showed that growth regulators induced little variation in plant height. Gibberellic acid (100 ppm) caused greater variation in height. 


\section{LITERATURA CITADA}

PAILEY, L.H. 1949 - Manual of cultivated plants. Mac Millan, New York. 851 1.

CASTRO, P.R.C.; CHURATA-MASCA, M.G.C. 1973 - Efeitos do cloreto de 2-cloroetil trimetilamônio na produtividade do tomateiro. Supl. Ciência e Cultura' 25(6): 530 .

GRAY, R.A. 1957 - Alteration of leaf size and shape and other changes caused by gibherellins in plants. Amer. J. Bot. 44(8): 674-682.

JENKINS, J.A. 1948 - The origin of the cultivated tomato. Econ. Bot. 2(4) : 379-392.

KNAVEL. D.E. 1969 - Influence of growth retardants on growth, nutrient content and yeld of tomato plants grown at various fertility levels. J. Amer. Soc. Hort. Sci. 94: $32-35$.

MIRANDA NETO, A.T.; CHAVES, J.R.P. 1969 - Efeito da aplicação dos ácidos giberélico e paracloro - fenoxiacético em tomateiro. Rev. Ceres 16(89) : 178-192.

MORGAN, J.V.; HENNERTY, M.J. 1968 - Some effects of growth regulator CCC and Alar (B 995) on the tomato (Lycopersicon esculentum Mill.). I. Effects on leaf area, plant spread, dry weight, height and leaf number. Sci. Proc. Roy. Dublin Soc. 2(14): $121-140$.

MULLfR, C.H. 1940 - A revision of the genus Lycopersicon. U. S. Depart. Agric. Misc. Publ. 382 : 29 p.

NORMAN, I.C. 1972 - The influence of succinic acid -2,2- dimethyl hydrazide (Alar-85) on tomato (Lycopersicon esculentum Mill.). Ghana J. Sci. 12(1): 51-57.

PLUMMER, T.H.; TOMES, M.L. 1958 - Effects of indolacetic acid and gibberellic acid on hormal and dwarf tomatoes. Bot. Gaz. 119: 197-200.

RAPPAPORT, L. 1957 - Effect of gibberellin on growth, flowering and fruiting of the Earlypack tomato, Lycopersicum esculentum. Plant Physiol. 32(5) : 440-444.

RICK. C.M. 1958 - The role of natural hybridization in the derivation of cultivated tomatoes of Western South America. Econ Bot. 12: 346-367.

SIMÃO, S.; SERZEDELLO, A.; WHITAKER, N. 1958 - Ação do ácido giberélico sobre o tomateiro (Lycopersicon esculentum Mill.). Rev. de Agric. 33(3) : 153-156.

TAHA, A.A.; KRETCHMAN, D.W.; JAWORSKI, C.A. 1975 - Plant regulator ef fects on plant quality, growth, development and yield of processing tomatoes. Outd. Veg. Crop Res., Ohio 81: 17-19.

WITTWER. S.H.; TOLBERT, N.E. $1960-$ (2-Chloroethyl) trimethylammonium chloride and related compounds as plant growth substances. III. Effect (n growth and flowering of the tomato. Amer. J. Bot. $47(7): 560-565$. 
